\title{
SEISMIC DESIGN OF LIQUID-CONTAINING CONCRETE STRUCTURES
}

\author{
by \\ Au Lu, B.Eng. \\ Ryerson University \\ Toronto, ON, Canada
}

\author{
A Project \\ Presented to Ryerson University \\ in partial fulfillment of the \\ requirements for the degree of \\ Master of Engineering \\ in the Program of \\ Civil.Engineering \\ Toronto, Ontario, Canada, 2010 \\ (C) Au Lu 2010 \\ PROPERTY OF




\section{AUTHOR'S DECLARATION}

I hereby declare that I am the sole author of this project. I authorize Ryerson University to lend this project to other institutions or individuals for the purpose of scholarly research.

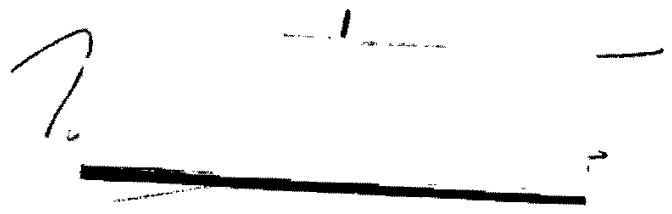

$\mathrm{Au} \mathrm{Lu}$

I further authorize Ryerson University to reproduce this project by photocopying or by other means, in total or in part, at the request of other institutions or individuals for the purpose of scholarly research.

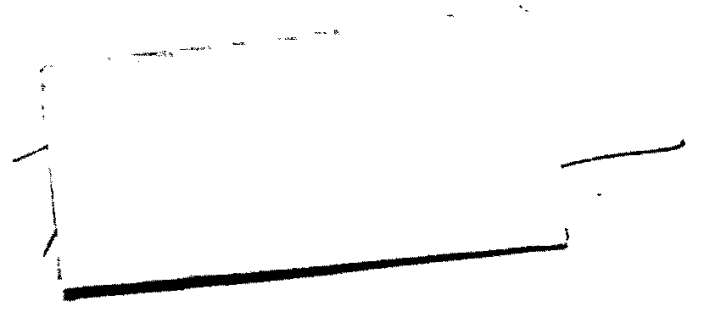

$\mathrm{Au} \mathrm{Lu}$ 


\section{BORROWERS}

Borrowers undertake to give proper credit for any use made for this project. Ryerson University requires the signatures of all persons using or photocopying this project.

\begin{tabular}{|c|c|c|c|}
\hline Name & Address & Date & Signature \\
\hline & & & \\
\hline & & & \\
\hline & & & \\
\hline & & & \\
\hline & & & \\
\hline & & & \\
\hline & & & \\
\hline & & & \\
\hline & & & \\
\hline & & & \\
\hline & & & \\
\hline & & & \\
\hline & & & \\
\hline & & & \\
\hline & & & \\
\hline & & & \\
\hline & & & \\
\hline & & & \\
\hline & & & \\
\hline & & & \\
\hline & & & \\
\hline & & & \\
\hline & & & \\
\hline & & & \\
\hline & & & \\
\hline & & & \\
\hline & & & \\
\hline & & & \\
\hline & & & \\
\hline & & & \\
\hline & & & \\
\hline & & & \\
\hline & & & \\
\hline & & & \\
\hline
\end{tabular}




\begin{abstract}
The seismic design of structures is a requirement for any places where earthquake occurs, and the design is based upon the codes that vary according to the jurisdictions in which the code was developed for. This study introduces and assesses the document ACI 350.3-06 which was developed by the ACI Committee to guide the design of liquid containing structures, and compares to other codes such as ACI 350.3-01 and NZS 3106 of New Zealand Standard. The importance of liquid containing structures cannot be stressed further, as it is apparent in nuclear applications.
\end{abstract}

The failure of tanks could be due to many reasons: 1) Shell buckling, caused by axial compression due to overall bending. 2) Roof damage as a result of sloshing of the upper portion of the containing liquid due to insufficient provision of freeboard. 3) Failure of inlets and outlets due to their inability to accommodate the deformations of the flexible tank. 4) Differential settlement or failure of supporting soil.

The pressures resulted from earthquake can cause catastrophic disaster, and they are the impulsive and convective mode which exerts pressures on the walls of the tank. The hydrodynamic model used to estimate these pressures in the ACI 350.3-06 document has also adopted earlier works from Housner, Veletsos, and Shivakumar. Throughout the years, the code has transformed tremendously, and this study shows that the codes are very similar in many ways, yet their differences can yield significantly different results. Furthermore, the results from the various codes are illustrated using the same example, and the validity of the results are determined as well.

The effects on seismic design due to the types of structure, whether the tank is rigid or flexible, and the support system are also introduced; moreover, their absences and the variations in the estimation of seismic parameters in some codes are also shown to have a large effect on the load estimation. 


\section{ACKNOWLEDGEMENTS}

I would like to thank, first and foremost, my supervisor, Dr. R. Kianoush for his patience and guidance throughout my undergrad and graduate studies. Without his encouragement, I probably would not have pursued my graduate studies from the start.

Many thanks go to mom and dad for their continuous support. It would be impossible without their help.

My gratitude also goes to my sister Doan who played an important role in helping me to choose Civil Engineering as my career.

I would also like to thank Sylvie and Phil for their love and for being there when I needed them. They have also motivated me to strive harder in life to achieve my goals. Their patience and support have shaped my life and allow me to become the person that I am. 


\section{TABLE OF CONTENTS}

Author's Declaration ii

Borrowers iii

Abstract iv

Acknowledgements $\mathrm{v}$

List of Tables viii

List of Figures .ix

1.0 Introduction \& Background Information 1

2.0 Seismic Design of Liquid-Containing Concrete Structures .. .4

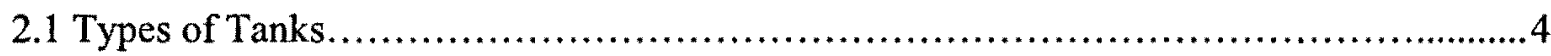

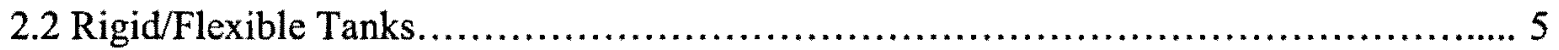

2.2.1 Rigidly Supported Rigid Tanks ................................................ 5

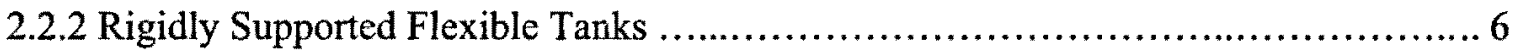

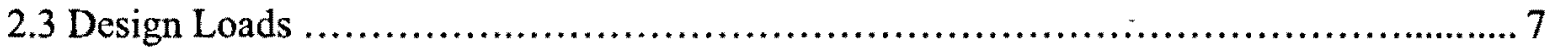

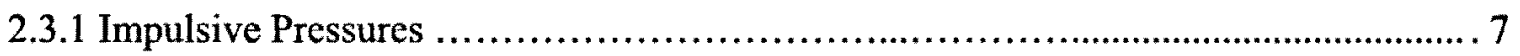

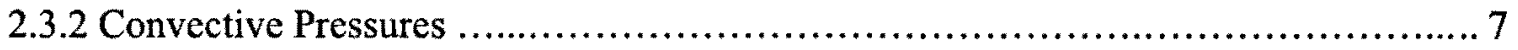

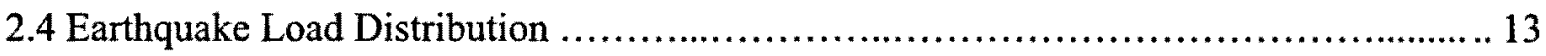

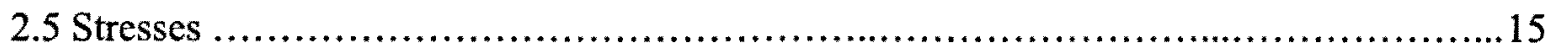

2.6 Earthquake Induced Earth Pressures ........................................... 16

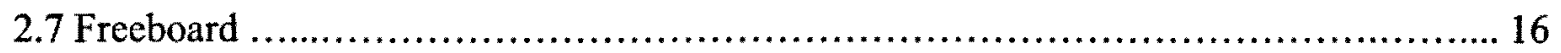


3.0 Comparison of $\mathrm{ACI} 350.3-06$ to $\mathrm{ACI} 350.3-01$

4.0 Comparison of ACI 350.3-06 to NZS 2010

5.0 Conclusion 32

References 


\section{LIST OF TABLES}

Table 2-1 Site Coefficient $F_{v}$ 9

Table 2-2 Site Coefficient $F_{a}$ (ASCE 7-05) 9

Table 2-3 Importance Factor (ACI350.3-06) 10

Table 2-4 Response Modification Factor (ACI350.3-06). 10

Table 3-1 Comparison of Response Modification Factor. 17

Table 3-2 Comparison Results of ACI350.3-06 to ACI350.3-06. 21

Table 4-1 Spectral Shape Factor C(T) .24

Table 4-2 Displacement Ductility Factor $\mu$ (DZ3106) 28

Table 4-3 Correction Factor $K_{f}(D Z$ 3106) .29

Table 4-4 Comparison Results of NZS3106 to ACI350.3-06 30 


\section{LIST OF FIGURES}

Fig 2-1 Typical Tank Configuration 4

Fig 2-2 Types of ground-supported, wall-to-footing connecting details .5

Fig 2-3 Hydrodynamic Pressure Distribution in Tank Walls 14

Fig 2-4 Vertical Force Distribution in Rectangular Walls (ACI350.3) 14

Fig 2-5 Distribution of hydrostatic and hydrodynamic pressures and inertia forces 15

Fig 4-1 Period $T_{c}$ for fundamental sloshing model .23

Fig 4-2(A) C(T) for MRS \& NITH .25

Fig 4-2(B) C(T) for Equivalent Static Method .26

Fig 4-3 Comparison of Proposed R-factors .27

Fig 4-4 ACI350.3-06 Equivalent Weights for Impulsive and Convective. .29

Fig 4-5 NZS3106 Equivalent Weights for Impulsive and Convective .29 


\subsection{INTRODUCTION \& BACKGROUND INFORMATION}

Earthquakes are the result of a sudden release of energy in the Earth's crust that creates seismic waves, which are measured in magnitudes on a Richter's scale. At the Earth's surface, the ground either experiences shaking motions or displacements. Minor earthquakes occur consistently in areas like California, Alaska, Guatemala, Chile, Peru, Indonesia, Iran, Pakistan, Azores, Turkey, New Zealand, Greece, Italy, and Japan, but they can occur anywhere in the world. Fortunately, larger earthquakes occur less frequently.

Since the 1930's, the number of seismic stations has increased from hundreds to thousands; this increase has allowed more earthquakes to be reported compared to the past, and it's not due to the increase in the number of earthquakes. USGS estimated that since 1990, there were an average of 18 major earthquakes and one great earthquake per year. Estimates of $90 \%$ of earthquakes occur along the 40,000-km long zone known as the Pacific Ring of Fire. And with a growing population in the high seismic risk areas, a single earthquake may claim millions of people (USGS).

Natural earthquakes are caused by movement of the Earth's tectonic plates, but human can stir a quake as well; such as coal mining, oil drilling, constructing large dams and buildings, etc. In 2008, the Sichuan Province of China experienced a quake that claimed 69,227 lives, and was recorded into history as the $19^{\text {th }}$ deadliest earthquake of all time. Natural earthquakes are not controllable, but human caused earthquakes are preventable.

Earthquakes can impact many things:

Shaking \& Ground rupture - the shaking and the ground rupture causes severe damages to building or other rigid structures, which is the main reason why seismic design of liquid containing structures is necessary.

Landslides \& Avalanches - the shaking can cause the slope to become unstable.

Fire - it can be generated by a break of the electrical power or gas lines. 
Soil liquefaction - because of the shaking, water saturated granular material loses it strength changes its state from solid to liquid, which may cause a building or other structures to tilt or sink as an example of 1964 Alaska earthquake.

Tsunami - In 2004, a tsunami occurred in the Indian Ocean claiming the lives of many people. Tsunamis are long-wavelength, long period sea waves produced by a sudden movement of large volumes of water. Generally, only earthquakes with a magnitude of 7.5 or greater on the Richter scale would cause tsunamis.

Floods - Floods can be indirectly caused by earthquakes when dams are destroyed as a result of the shaking motion.

Due to the importance of fluid containers in nuclear reactors, the design of liquid containing concrete structures in seismic zones is becoming critical. Nuclear reactors are just one of the significant applications, others include municipal water supply, fire fighting systems, oil tanks, liquefied natural gas, and chemical fluids. The failure of the latter types of containing structure would result in a catastrophic and costly situation such as water shortages, pollution, contamination, or prevent fire-fighting at critical times (Veletsos \& Shivakumar, 1996).

The failure of tanks could be due to many reasons:

1) Shell buckling, caused by axial compression due to overall bending.

2) Roof damage as a result of sloshing of the upper portion of the containing liquid due to insufficient provision of freeboard.

3) Failure of inlets and outlets due to their inability to accommodate the deformations of the flexible tank.

4) Differential settlement or failure of supporting soil.

As the number of these types of tanks increase, so is the need to understand their behaviour; therefore, many research studies have been conducted to examine the dynamic response of liquid containing tanks subjected to accelerations, and they were done independently by Veletsos and Shivakumar from Rice University, and George Housner. Housner's objective was to deliver 
expressions related to impulsive and convective components of pressure as a result of accelerations due to earthquake; many of his equations were used in the ACI350.3 document.

Veletsos and Shivakumar's objectives were to:

1) Provide an overview of the aspects of the response of cylindrical tanks storing a homogenous liquid subjected to earthquake.

2) To present information and concepts of which the hydrodynamic effects may be evaluated.

3) To describe the procedure to analyze tanks of inhomogeneous, layered liquids.

4) To highlight the interrelationship of responses obtained for tanks containing a homogenous liquid, and a homogenous, viscoelastic solid.

In 2006, the American Concrete Institute have revised the journal ACI350.3-01 and established a new set of journal named ACl350.3-06. This journal provides codes and guidelines to design circular and rectangular concrete tanks in seismic zones, and the design of seismic liquid containing structures will be discussed in accordance with this provision. 


\subsection{SEISMIC DESIGN OF LIQUID CONTAINING CONCRETE STRUCTURES}

\subsection{Types of Tanks}

The liquid containing structures in ACI350.3-06 are ground-supported and pedestal mounted structures which includes circular and rectangular concrete structures, on grade and below grade. The following figures illustrate a circular and a rectangular tank with $\mathrm{H}_{W}$ as the height of the wall, and $\mathrm{H}_{\mathrm{L}}$ as height of liquid, $\mathrm{B}$ and $\mathrm{L}$ as length and width of the rectangular tank, respectively, and D as the diameter of the circular tank (ACI350.3-06, 2006).
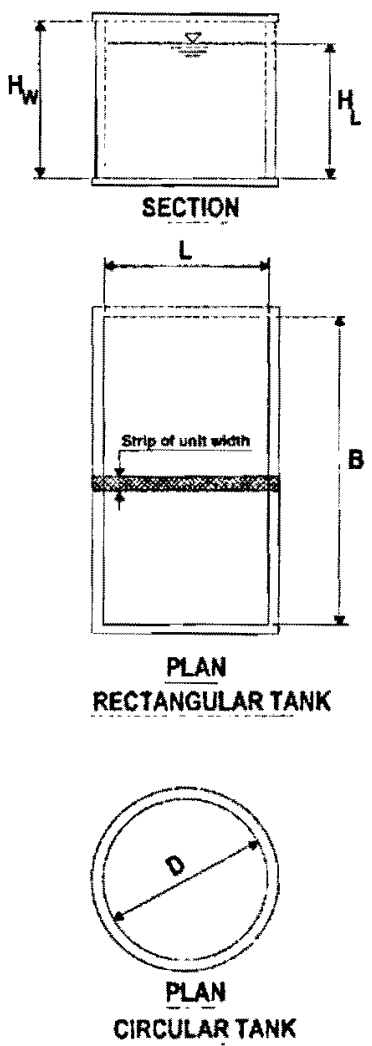

Fig 2-1 Typical Tank Configuration (ASCE, 1984)

Rectangular tanks are limited to fixed base, and hinged base, whereas, circular also includes flexible base. For fixed and hinged base, the method of construction can be reinforced or prestressed, but for flexible base, they must be prestressed. See the following figures. 


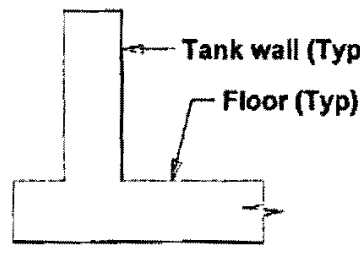

FIXED

TYPE 1.1 or 2.1
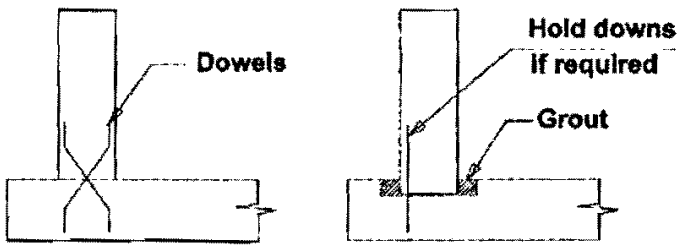

HINGED or PINNED

TYPE 1.2 or 2.2

\section{NONFLEXIBLE BASE CONNECTIONS}

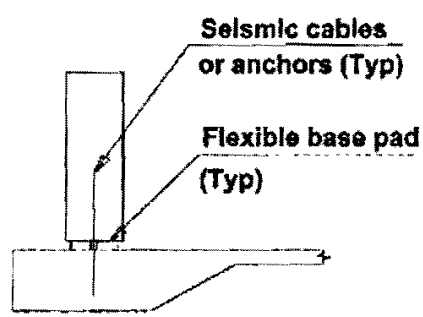

ANCHORED

FLEXIBLE BASE

TYPE 2.3(1)

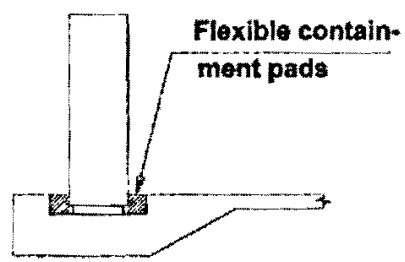

UNANCHORED

FLEXIBLE BASE

TYPE 2.3(2)

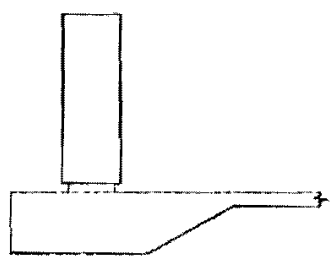

FLEXIBLE BASE

TYPE 2.3(3)

\section{FLEXIBLE BASE CONNECTIONS}

Fig 2-2 Types of ground-supported, wall-to-footing connecting details (base watertops not shown) (ACI 350.3-06, 2006)

ACI350.3-06 also includes pedestal-mounted structures, which means that the liquid containing structures are mounted on cantilever-type pedestals.

\subsection{Rigid/Flexible Tanks}

\subsubsection{Rigidly Supported Rigid Tanks}

There are three (3) elements to these systems that attract people to perform studies for this type of support:

1) Their response can easily be computed.

2) The need to understand the response of rigidly supported tanks is necessary prior to the study of flexible tanks. 
3) The expressions for rigid tanks could be modified

Veletsos \& Shivakumar had illustrated, in their study, rigid tanks as a system where no vertical motion of the contained liquid occurred and where the liquid is free to move. Where there is no vertical motion, the liquid acts in unison with the tank wall as a rigid body, and the resulting instantaneous hydrodynamic pressure is

$$
P(\eta, \theta, \mathfrak{t})=\rho R x_{g}(t) \cos \theta
$$

Where $x_{g}(t)$ is the acceleration at anytime $t$.

Please note from the above equation that the pressure is proportional to the ground acceleration, and the pressure is uniformly distributed in the vertical or axial direction, but varies in the circumferential direction as a cosine function.

For free moving liquid, only a portion of contained liquid in the lower part of the tank synchronizes with the tank wall as it was rigidly attached to it which is known as the impulsive component, and the rest sloshes which is the convective component (Housner, 1963).

\subsubsection{Rigidly Supported Flexible Tanks}

The impulsive component of the hydrodynamic pressure is highly dependent on the flexibility of the tank wall. On the other hand, the convective component is independent of the tank wall's flexibility because they are associated with natural periods of vibration which are significantly longer than dominant periods of ground motion. The impulsive component is generally described as a mass rigidly attached to the wall, so for any motion that the wall encounters, the liquid would behave the same. For a rigid tank, the wall motion is the same as that of the ground, but for a flexible tank, the motion is rather complex. The maximum values of the impulsive components of flexible tanks could be smaller, same or even larger than rigid tanks, and it depends on the interrelationship of the predominant frequencies of the ground motion and the impulsive natural frequencies of the tank liquid system. Though generally, the hydrodynamic effects for flexible tanks are significantly larger than those of rigid tanks (Veletsos \& Shivakumar, 1996). 


\subsection{Design Loads}

For seismic design, the walls of liquid-containing structures are to be designed for the following forces $(A C 1350.3-06,2006)$ :

1) Inertia forces $P_{w}$ and $P_{r}$ (force from the wall and roof);

2) Hydrodynamic impulsive force $P_{i}$;

3) Hydrodynamic convective force Pc from the contained liquid;

4) Dynamic earth pressure from saturated and unsaturated soils against the buried portion of the wall;

5) The effects of vertical acceleration.

\subsubsection{Impulsive Pressures}

Impulsive pressures are inertial forces produced by accelerations of the walls of the container and are given by

$P_{i}=C_{j} I\left(W_{i} / R_{i}\right)$

Because the impulsive pressures are produced by seismic accelerations of the tank walls, the impulsive force is evenly divided into a pressure force on the wall accelerating into the fluid, and a suction force on the wall accelerating away from the fluid. This force generally stresses the tank wall. When earthquake occurs, the impulsive force changes direction multiple times per second, which also changes the direction of the acceleration in the base; therefore, the overturning moment generated by impulsive force is not effective in tending the overturning tank. However, the convective force is a different scenario (Housner, 1963).

\subsubsection{Convective Pressures}

Convective pressures are produced by oscillations of the fluid, and therefore is also a result of impulsive pressures. The period of oscillation is dependent on the ratio of fluid depth to tank diameter. Convective pressure may have the tendency to uplift the tank wall if there is inadequate weight to hold it down. Convective force fluctuates sinusoidally with a period of 
vibration that depends on the dimension of the tank, and the sloshing can be anywhere between 20 to 40 seconds for earthquakes of magnitude 6.5 to 7.5. The sloshing may increase or decrease the fluid pressure on the wall. When designing for convective pressure, the designer must ensure sufficient weight in the tank to avoid uplifting (Housner, 1963).

$P_{c}=C_{c} I\left(W_{c} / R_{c}\right)$

All dynamic lateral forces above the base shall be determined in accordance with Section 4 of $\mathrm{ACl} 350.3-06$.

$C_{i}$ and $C_{c}$ is the response coefficients determined in accordance with Sections 9.4 of ACI350.3, which is also in accordance with ASCE 7-05. An essential parameter for the seismic design of concrete structures is the seismic response coefficient (C), which, when multiplied by the weight of the structure, gives the base shear force for seismic design. This coefficient could be determined from the spectral acceleration.

The determination of the seismic response coefficients is dependent on:

1) the design spectral response acceleration at short periods $\left(S_{\mathrm{ds}}\right)$;

2) the design spectral acceleration at a 1 second period $\left(\mathrm{S}_{\mathrm{d} 1}\right)$;

3) the mapped spectral accelerations at short periods $\left(S_{s}\right)$ and at 1 second $\left(S_{1}\right)$;

4) the site coefficients $F_{a}$, and $F_{v}$;

5) the periods $T_{i}, T_{c}$, and $T_{v}$

The design spectral response accelerations at short periods are dependent on the site class and the maximum ground-shaking intensity at a given location. The site class is based on a site's soil properties, which can range from hard rock (Site Class A) to peat and clays (Site Class F). If the soil properties are not known in sufficient detail, Site Class D may be assumed (ACI350.3-06, 2006). The values of the site class coefficient are listed below. The Ground shaking intensity can be obtained from the database of the U.S. Geological Survey using latitudes and longitudes or zip codes. 


\begin{tabular}{|c|c|c|c|c|c|}
\hline \multirow{2}{*}{$\begin{array}{c}\text { Site } \\
\text { Class }\end{array}$} & \multicolumn{5}{|c|}{ Response Acceleration $\mathrm{S}_{1}$} \\
\cline { 2 - 6 } & $\leq 0.10$ & 0.20 & 0.30 & 0.40 & $\geq 0.50$ \\
\hline A & 0.8 & 0.8 & 0.8 & 0.8 & 0.8 \\
\hline B & 1.0 & 1.0 & 1.0 & 1.0 & 1.0 \\
\hline C & 1.7 & 1.6 & 1.5 & 1.4 & 1.3 \\
\hline D & 2.4 & 2.0 & 1.8 & 1.6 & 1.5 \\
\hline E & 3.5 & 3.2 & 2.8 & 2.4 & 2.4 \\
\hline F & (a) & (a) & (a) & (a) & (a) \\
\hline
\end{tabular}

Table 2-1 Site Coefficient $\mathrm{F}_{\mathrm{v}}(A S C E 7-05,2005)$

Note: (a) Site-specific geotechnical investigation \& dynamic site response analysis required, except $T<0.5 \mathrm{~s}$.

The formula for the design spectral response accelerations at short periods is given by the formula

$$
\mathrm{S}_{\mathrm{ds}}=2 \mathrm{~S}_{\mathrm{s}} F_{\mathrm{a}} / 3
$$

Where $S_{\mathrm{ds}}=2 S_{\mathrm{ms}} / 3$

$\mathrm{S}_{\mathrm{ms}}$ is the maximum earthquake spectral-response acceleration over short periods determined by

$$
\mathrm{S}_{\mathrm{ms}}=\mathrm{F}_{\mathrm{a}} \mathrm{S}_{\mathrm{s}}
$$

\begin{tabular}{|c|c|c|c|c|c|}
\hline \multirow{2}{*}{$\begin{array}{c}\text { Site } \\
\text { Class }\end{array}$} & \multicolumn{5}{|c|}{ Response Acceleration Ss } \\
\cline { 2 - 6 } A & $\leq 0.25$ & 0.50 & 0.75 & 1.00 & $\geq 1.25$ \\
\hline B & 0.8 & 0.8 & 0.8 & 0.8 & 0.8 \\
\hline C & 1.0 & 1.0 & 1.0 & 1.0 & 1.0 \\
\hline D & 1.2 & 1.2 & 1.1 & 1.0 & 1.0 \\
\hline E & 2.5 & 1.4 & 1.2 & 1.1 & 1.0 \\
\hline F & (a) & 1.7 & 1.2 & 0.9 & 0.9 \\
\hline
\end{tabular}

Table 2-2 Site Coefficient $F_{a}(A S C E$ 7-05, 2005)

Note: (a) Site-specific geotechnical investigation \& dynamic site response analysis required, except $T<0.5 \mathrm{~s}$.

Combining both equations resulted with the design spectral acceleration at short periods.

The design spectral accelerations at 1 sec can be calculated using the following equations: 


$$
\mathrm{S}_{\mathrm{dl}}=2 \mathrm{~S}_{\mathrm{ml}} / 3
$$

Where $\mathrm{S}_{\mathrm{ml}}$ is the maximum considered earthquake spectral response acceleration at $1 \mathrm{sec}$, as determined by

$$
\mathrm{S}_{\mathrm{ml}}=\mathrm{F}_{\mathrm{v}} \mathrm{S}_{1}
$$

By combining both of the above equations results in

$$
\mathrm{S}_{\mathrm{d} 1}=2 \mathrm{~F}_{\mathrm{v}} \mathrm{S}_{1} / 3
$$

The $2 / 3$ factor is a design element that accounts for reserve capacity against collapse in structures.

The seismic response coefficients $C_{i}$ is then determined using equations $9-32$ through 9-34 in ACI350.3-06.

$\mathrm{I}$ is the importance factor which is determined from Table 4.1.1(a) of the ACl350.3

\begin{tabular}{|c|c|c|}
\hline Categories & Tank Use & Factor I \\
\hline III & Tanks containing hazardous materials * & 1.5 \\
\hline $\begin{array}{c}\text { Tanks that are intended to remain } \\
\text { usable for emergency puposes after an } \\
\text { earthquake, or tanks that are part of } \\
\text { lifeline systems }\end{array}$ & 1.25 \\
\hline I & Tanks not listed in Categories II or III & 1 \\
\hline
\end{tabular}

Table 2-3 Importance Factor (AC1350.3-06, 2006). *In some cases, for tanks containing hazardous materials, engineering judgement may require a factor $I>1.5$.

$R_{i}$ and $R_{c}$ is the response modification factor and is determined from Table 4.1.1(b) of the ACI350.3 and is also shown below.

\begin{tabular}{|l|c|c|c|}
\hline Type of structure & $R_{\mathrm{i}}$ on or above grade & Buried* $^{*}$ & $R_{w c}$ \\
\hline (a) Anchored, flexible-base tanks & 3.25 & $3.25 \dagger$ & 1.00 \\
\hline (b) Fixed or hinged-base tanks & 2.00 & 3.00 & 1.00 \\
\hline (c) Unanchored, contained, or uncontained tanks $¥$ & 1.50 & 2.00 & 1.00. \\
\hline (d) Pedestal mounted tanks & 2.00 & - & 1.00 \\
\hline
\end{tabular}

Table 2-4 Response Modification Factor (ACI350.3-06, 2006) 
*Buried tank is defined as a tank whose maximum water surface at rest is at or below ground level. For partially buried tanks, the Ri value may be linearly interpolated between that shown for tanks on grade, and for buried tanks.

$\dagger R i=3.25$ is the maximum Ri value permitted to be used for any liquid-containing concrete structure.

$\neq$ Unanchored, uncontained tanks may not be built in locations where Ss $\geq 0.75$.

$\mathrm{W}_{\mathrm{i}}$ and $\mathrm{W}_{\mathrm{c}}$ is the equivalent weight of the liquid.

For rectangular tanks, $\mathrm{W}_{\mathrm{i}} / \mathrm{W}_{\mathrm{L}}=\tanh \left[0.866\left(\mathrm{~L} / \mathrm{H}_{\mathrm{L}}\right)\right] /\left[0.866\left(\mathrm{~L} / \mathrm{H}_{\mathrm{L}}\right)\right]$

The latter equation was originally developed by Housner and is presented hereafter.

$$
\mathrm{m}_{0}=-2 \mathrm{P} / \mathrm{u}=2 \operatorname{ph}^{2} \tanh \left[(3)^{1 / 2}\left(1 / \mathrm{H}_{\mathrm{L}}\right)\right] /\left[(3)^{1 / 2}\left(1 / \mathrm{H}_{\mathrm{L}}\right)\right]=\mathrm{m} \tanh \left[(3)^{1 / 2}\left(1 / \mathrm{H}_{\mathrm{L}}\right)\right] /\left[(3)^{1 / 2}\left(1 / \mathrm{H}_{\mathrm{L}}\right)\right]
$$

by substituting $1=L / 2$, the equation becomes

$$
\mathrm{m}_{0}=\mathrm{m} \tanh \left[0.866\left(\mathrm{~L} / \mathrm{H}_{\mathrm{L}}\right)\right] /\left[0.866\left(\mathrm{~L} / \mathrm{H}_{\mathrm{L}}\right)\right]
$$

If we multiply the equation by $\mathrm{g}$, acceleration due to gravity, we would get $\mathrm{W}_{\mathrm{i}}$. Similar holds true for circular tanks.

For circular tanks, $\mathrm{W}_{\mathrm{i}} / \mathrm{W}_{\mathrm{L}}=\tanh \left[0.866\left(\mathrm{D} / \mathrm{H}_{\mathrm{L}}\right)\right] /\left[0.866\left(\mathrm{D} / \mathrm{H}_{\mathrm{L}}\right)\right]$. Housner have developed

$$
m_{0}=-P / u=\rho \pi R^{2} H_{L} \tanh \left[(3)^{1 / 2} R / H_{L}\right] /\left[(3)^{1 / 2} R / H_{L}\right]=m \tanh \left[(3)^{1 / 2} R / H_{L}\right] /\left[(3)^{1 / 2} R / H_{L}\right] \text {; }
$$

by substituting $R=D / 2$, we get

$$
\mathrm{m}_{0}=\mathrm{m} \tanh \left[0.866 \mathrm{D} / \mathrm{H}_{\mathrm{L}}\right] /\left[0.866 \mathrm{D} / \mathrm{H}_{\mathrm{L}}\right]
$$

For convective rectangular tanks, $W_{c}=0.264\left(\mathrm{~L} / \mathrm{H}_{\mathrm{L}}\right) \tanh \left[3.16\left(\mathrm{H}_{\mathrm{L}} / \mathrm{L}\right)\right]$; Housner have developed

$$
\begin{aligned}
& \mathrm{m}_{1} \mathrm{~A}_{1}=(2 / 3) \rho \mathrm{l}^{3} \theta_{\mathrm{h}} \\
& \mathrm{A}_{1}=(2 / 3)(2 / 5)^{1 / 2} \mathrm{\rho l}^{4} \theta_{\mathrm{h}}{ }^{2}\left(1 / \mathrm{m}_{1} \mathrm{~A}_{1}\right) \operatorname{coth}(5 / 2)^{1 / 2} \mathrm{H}_{\mathrm{L}} / 1
\end{aligned}
$$

Solving the preceding equations give 


$$
\left.\mathrm{m}_{1}=\mathrm{m}(1 / 3)(5 / 2)^{1 / 2}\left(1 / \mathrm{H}_{\mathrm{L}}\right) \tanh \left[(5 / 2)^{1 / 2} \mathrm{H}_{\mathrm{L}} / 1\right)\right]
$$

by substituting 1 by $L / 2$, we get

$$
\left.\mathrm{m}_{1}=\mathrm{m} 0.264\left(\mathrm{~L} / \mathrm{H}_{\mathrm{L}}\right) \tanh \left[3.16 \mathrm{H}_{\mathrm{L}} / \mathrm{L}\right)\right]
$$

which is the same as the code provision in ACI350.3.

For circular tanks, $\mathrm{W}_{\mathrm{c}}=0.230\left(\mathrm{D} / \mathrm{H}_{\mathrm{L}}\right) \tanh \left[3.68\left(\mathrm{H}_{\mathrm{L}} / \mathrm{D}\right)\right]$, Housner have developed

$$
\begin{aligned}
& \mathrm{m}_{1} \mathrm{~A}_{1}=(1 / 4) \pi \rho \mathrm{R}^{4} \theta_{\mathrm{h}} \\
& \left.\mathrm{m}_{1} \mathrm{~A}_{1}=(1 / 4)(8 / 27)^{1 / 2} \rho \mathrm{R}^{5} \Gamma_{\mathrm{h}}{ }^{2} \operatorname{coth}[)(27 / 8)^{1 / 2} \mathrm{H}_{\mathrm{L}} / \mathrm{R}\right]
\end{aligned}
$$

solving the above equations give

$$
\left.\mathrm{m}_{1}=\mathrm{m} 0.46\left(\mathrm{R} / \mathrm{H}_{\mathrm{L}}\right) \tanh \left[(27 / 8)^{1 / 2} \mathrm{H}_{\mathrm{L}} / \mathrm{R}\right)\right]
$$

by substituting $R$ by $D / 2$, we get

$$
\mathrm{m}_{1}=\mathrm{m} 0.230\left(\mathrm{D} / \mathrm{H}_{\mathrm{L}}\right) \tanh \left[3.68\left(\mathrm{H}_{\mathrm{L}} / \mathrm{D}\right]\right)
$$

$\mathrm{m}_{0}$ is the equivalent mass of the fluid;

$m$ is the mass of the liquid;

$\mathrm{P}$ is the total force;

$\mathrm{u}$ is the fluid acceleration;

$\rho$ is the density of the liquid;

$\mathrm{H}_{\mathrm{L}}$ is the height of the liquid;

1 is $L / 2$ and $L$ is the length of the inside of the rectangular tank parallel to the direction of ground motion;

$\mathrm{R}$ is radius of circular tanks;

$\mathrm{D}$ is diameter of circular tank; 
The moments are then calculated in accordance to Section 4 of ACI350.3-06.

\subsection{Earthquake Load Distribution}

All joints of tanks must be designed to withstand shear transfer of the horizontal pressures. Wall to wall, wall to floor, and wall to roof joints of rectangular tanks must be designed on the basis the following shear transfer mechanism:

1) Walls perpendicular and parallel to the direction of ground motion being investigated would be analyzed as slabs and shear-walls, respectively, and is computed in accordance to Section 5.3 of $\mathrm{ACI} 350.3-06$.

2) The shears along top, side and bottom should correspond to the slab reactions.

For circular tanks, the design is simpler than that of rectangular tanks, only the wall to footing, and wall to roof joints must be designed to withstand earthquake shear forces.

In circular tanks, the maximum tangential shear occurs at a point on the tank wall oriented 90 degrees to the earthquake direction. Whereas, the radial shear is maximum at 0 and 180 degrees to the ground motion. The maximum radial shear can be computed using cylindrical shell theory. Radial shear is created by flexural response of the wall near the base, and is proportional to the hydrodynamic forces. All seismic design should design the reinforcement to transmit the shear through the wall-footing joint $(A C 1350.3-06,2006)$.

The design for shear is significant as the wall of the tank may slide if the shear is not transferred by any means. In unanchored flexible base, it is assumed that the shear is transmitted by means of friction only. If friction is not adequate to resist the earthquake shear, then mechanical restraint may be required $(A C I 350.3-06,2006)$.

The hydrodynamic pressure distribution in tank walls is illustrated below. 

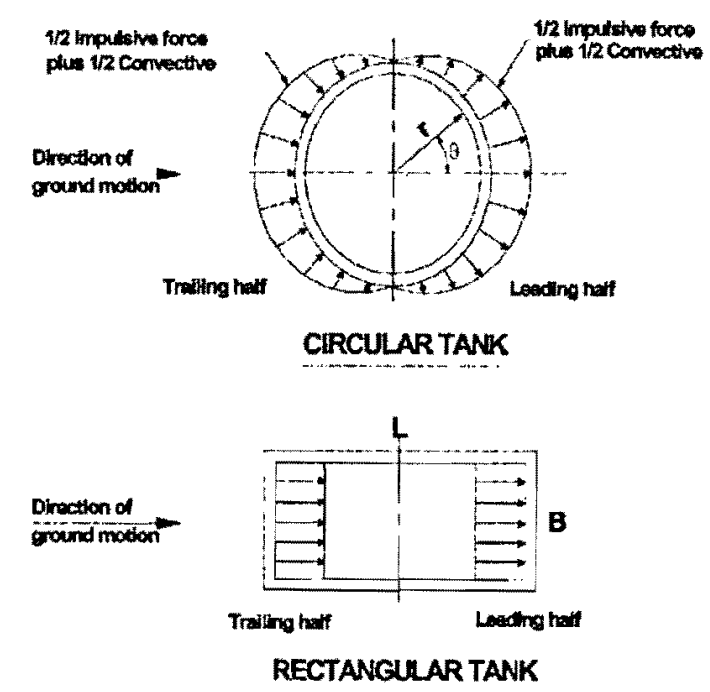

Fig 2-3 Hydrodynamic Pressure Distribution in Tank Walls (Housner, 1963)

For the distribution of rectangular tanks, see illustration below.

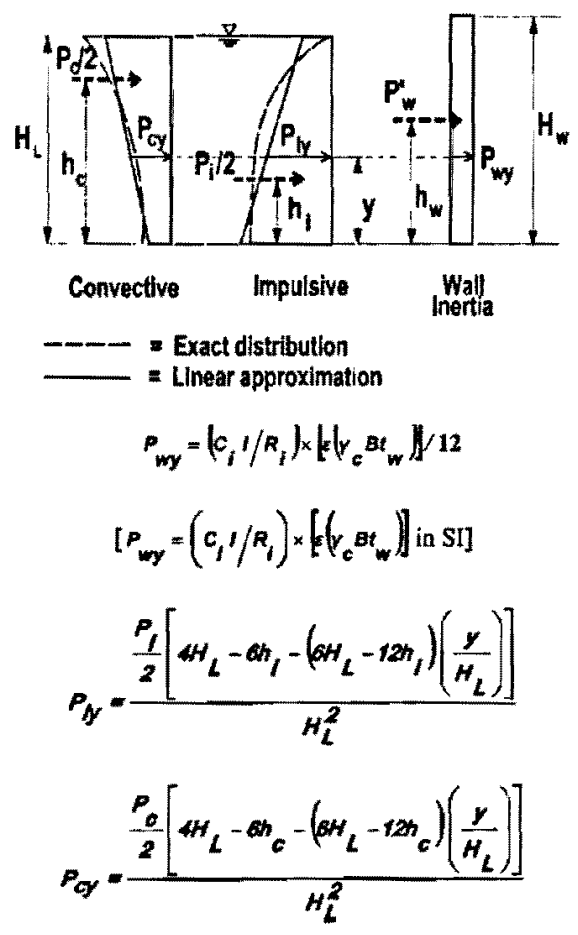

Fig 2-4 Vertical Force Distribution in Rectangular Walls (ACI350.3-06, 2006)

For the distribution of circular tanks, see figure below. 
The below figures illustrate the distribution of hydrostatic and hydrodynamic pressures and inertia forces on the wall of a rectangular liquid-containing structure.
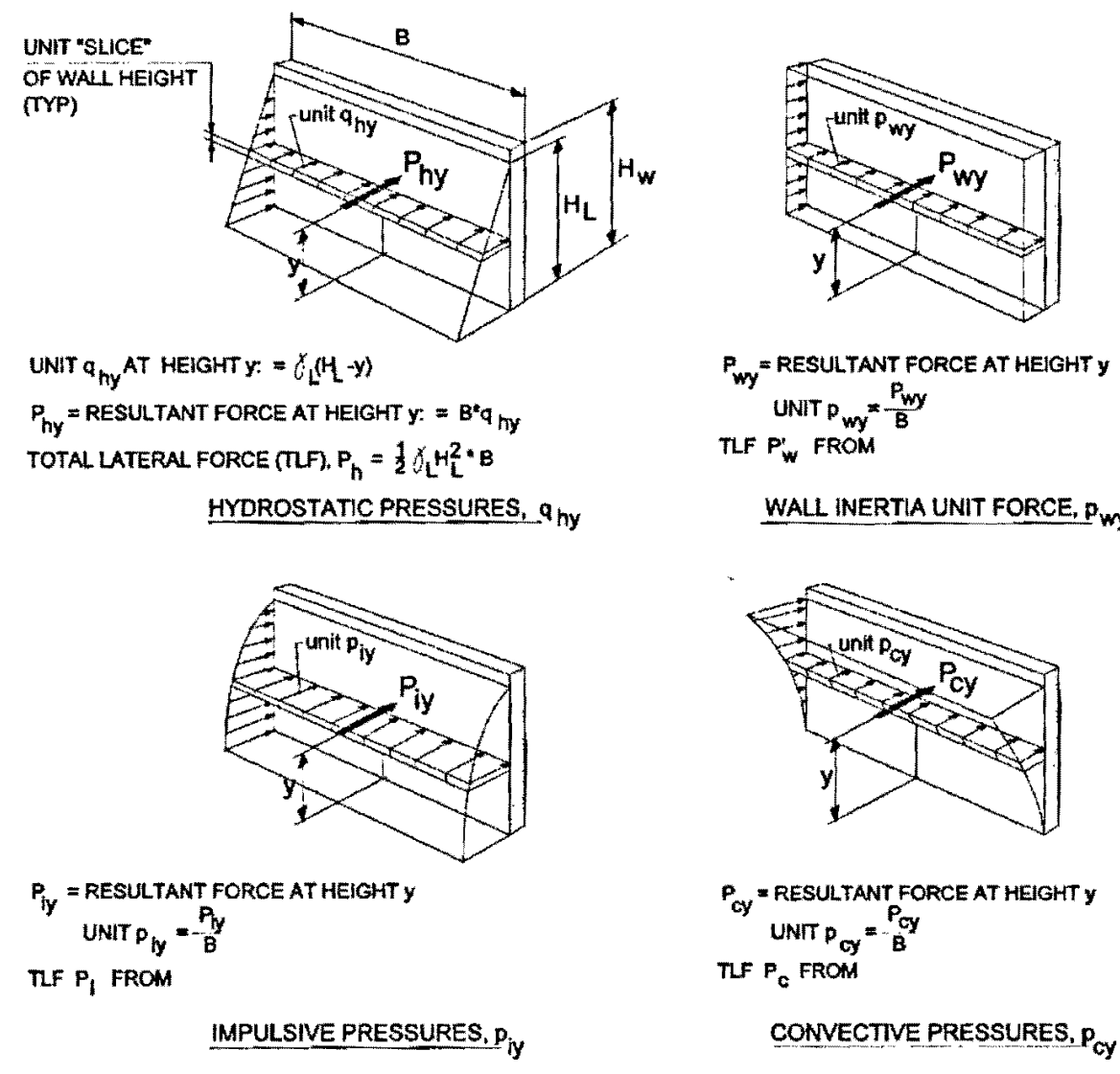

WALL INERTIA UNIT FORCE, pwy

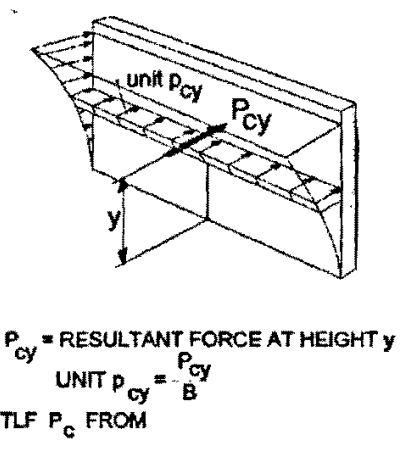

CONVECTIVE PRESSURES, $\mathrm{p}_{\mathrm{CY}}$

Fig 2-5 Distribution of hydrostatic and hydrodynamic pressures and inertia forces on the wall of a rectangular liquid-containing structure (Haroun, 1984).

\subsection{Stresses}

In rectangular tanks, the vertical and horizontal bending stresses and shear stresses in the wall and at the wall base due to lateral earthquake forces shall be computed on the basis of slab action using pressure distribution. For circular tanks, the vertical bending stresses and shear stresses in the wall and at the wall base due to lateral earthquake forces shall be computed on the basis of shell action. When computing vertical bending moments in the walls of rectangular and circular tanks, the boundary conditions at the wall to base, and wall to roof joints should be properly accounted for $(A C 1350.3-06,2006)$. The hoop forces in the circular wall at a liquid level $y$ above the tank base can be determined as 


$$
\mathrm{N}_{\mathrm{y}}=\left[\left(\mathrm{N}_{\mathrm{iy}}+\mathrm{N}_{\mathrm{wy}}\right)^{2}+\mathrm{N}_{\mathrm{cy}}{ }^{2}+\mathrm{N}_{\mathrm{hy}} 2\right]^{2}
$$

And the corresponding stress is

$$
\sigma_{\mathrm{y}}=\mathrm{N}_{\mathrm{y}} / \mathrm{t}_{\mathrm{w}}
$$

and all of the relevant equations for stress computations are presented in ACI350.3-06.

\subsection{Earthquake Induced Earth Pressures}

When designing a buried liquid-containing structure or the walls, dynamic earth pressure must be accounted for; the effects of groundwater table must also be accounted for, if present. K should always be used in determining earth pressure unless it can be demonstrated that $\mathrm{K}$, the coefficient of lateral earth pressure, is between $\mathrm{K}$ and $\mathrm{K}_{\mathrm{a}}$. It could also be assumed that the seismic component of earth pressure act at 0.6 of earth height above the tank base. When the water table is above the structure, the resultant of the incremental increase in the groundwater pressure shall be assumed to act at $1 / 3$ of the water depth above the base. In addition, for any buried tanks, the dynamic backfill forces should not be relied on to reduce the dynamic effects of the stored liquid or vice versa $(A C I 350.3-06,2006)$.

\subsection{Freeboard}

The maximum vertical displacement of the liquid, also known as slosh height, $d_{\max }$, must be designed for to avoid roof damage or over-spilling. If the freeboard cannot be accommodated, the level of the contained liquid must be lowered or the roof must be designed such that it can withstand the sloshing pressure from the liquid, or provide an overflow spillway (ACI350.3-06, 2006). The slosh height can be calculated as

$$
\begin{array}{ll}
d_{\max }=L_{C} I / 2 & \text { for rectangular tanks } \\
d_{\max }=D C_{c} I / 2 & \text { for circular tanks }
\end{array}
$$

Where site-specific response spectra are considered, $d_{\max }$ is calculated in accordance to Section R7.1 from ACI350.3-06. 


\subsection{COMPARISON OF ACI350.3-06 TO ACI350.3-01}

Within the five (5) year time frame, the $\mathrm{ACI}$ has revised the codes with some major changes. The main modification between the two codes is the estimation of the dynamic lateral pressures, $P$. In the new code, the seismic zone factor, $Z$, and the soil profile coefficient, $S$, has been eliminated, and it currently adapts the guidelines in ASCE 7-05 to account for spectral response. Basically, the products of ZSC (site hazard coefficient, soil profile coefficient, and the site response) of the old code have been replaced by a single parameter $\mathrm{C}$, response coefficient in the new code ACl350.3-06. New parameters, from ASCE 7-05, were introduced into ACI350.3-06 such as the mapped spectral response accelerations at short periods, $S_{s}$, and at 1 second, $S_{1}$. Other new parameters are the site coefficient for short-periods, $F_{v}$, and 1 second, $F_{a}$. It can be said that by adapting ASCE 7-05 into this new revision, the design has become more complicated, but perhaps a lower margin of errors can be achieved. A single value of the site hazard coefficient, $Z$, was used to represent a range of spectral accelerations in the old code. In the new code, the seismic response is actually computed based on the exact spectral accelerations, which would result in a precise estimation of the dynamic lateral pressures, $P$.

In addition, the values assigned to the response modification factor for impulsive pressures, $R_{i}$, has been reduced. Since $R_{i}$ is inversely proportional to the impulsive pressure, $P_{i}$, the estimation of $\mathrm{P}_{\mathrm{i}}$ becomes higher, and therefore more conservative. The table below lists the values of the response modification factor in the old and new code. It can also be seen that the values of the response modification factor for convective pressure remains unchanged.

\begin{tabular}{|l|c|c|c|c|c|c|}
\hline & \multicolumn{3}{|c|}{ ACI 350.3-01 } & \multicolumn{3}{c|}{ ACI 350.3-06 } \\
\hline Type of structure & $\begin{array}{c}\text { Ri on or } \\
\text { above } \\
\text { grade }\end{array}$ & Buried & RwC & $\begin{array}{c}\text { Ri on or } \\
\text { above } \\
\text { grade }\end{array}$ & Buried & Rwc \\
\hline (a) Anchored, flexible-base tanks & 4.50 & 4.50 & 1.00 & 3.25 & 3.25 & 1.00 \\
\hline (b) Fixed or hinged-base tanks & 2.75 & 4.00 & 1.00 & 2.00 & 3.00 & 1.00 \\
\hline $\begin{array}{l}\text { (c) Unanchored, contained, or } \\
\text { uncontained tanks }\end{array}$ & 2.00 & 2.75 & 1.00 & 1.50 & 2.00 & 1.00 \\
\hline (d) Pedestal mounted tanks & 3.00 & - & 1.00 & 2.00 & - & 1.00 \\
\hline
\end{tabular}

Table 3-1 Comparison of Response Modification Factor 
Other than the two previously identified modifications, all other code provisions remain unchanged. The following example is used to illustrate the design utilizing ACI 350.3-06.

\section{Example 3.1}

A water tank is to be situated in a high seismic zone where the spectral accelerations are $\mathrm{S}_{\mathrm{s}}=150 \%$ and $\mathrm{S}_{1}=60 \%$. The tank is reinforced concrete with a fixed base, and it is above ground without a roof. In addition, this tank will not be used for emergency purposes. It has a diameter $\mathrm{D}=30 \mathrm{~m}$, height $\mathrm{H}=6 \mathrm{~m}$ with a wall thickness $\mathrm{t}_{\mathrm{w}}=300 \mathrm{~mm}$, and the height of liquid can be assumed to be $\mathrm{H}_{\mathrm{L}}=6 \mathrm{~m}$, and the soil classification is Site Class B.

Solution:

$\begin{array}{lll}D= & 30.0 & \mathrm{~m} \\ t_{w}= & 300 & \mathrm{~mm} \\ t_{L}= & 0.0 & \mathrm{~mm} \\ H_{L}= & 6.0 & \mathrm{~m} \\ H_{W}= & 6.00 & \mathrm{~m} \\ H_{W}(\min )= & 6.69 & \mathrm{~m}\end{array}$

Provide a freeboard allowance or Overflow spillway

$\begin{array}{lcl}\mathrm{g}_{\mathrm{L}}= & 9.8 & \mathrm{KN} / \mathrm{m}^{3} \\ \mathrm{~g}_{\mathrm{C}}= & 23.6 & \mathrm{KN} / \mathrm{m}^{3} \\ \mathrm{r}_{\mathrm{L}}= & 1 & \mathrm{KN} \cdot \mathrm{S}^{2} / \mathrm{m}^{4} \\ \mathrm{r}_{\mathrm{C}}= & 2.4 & \mathrm{KN} \cdot \mathrm{S}^{2} / \mathrm{m}^{4} \\ \mathrm{f}_{\mathrm{c}}= & 28 & \mathrm{Mpa} \\ \mathrm{E}_{\mathrm{c}}= & 25047.8 \mathrm{Mpa}\end{array}$

Seismic Mapped Spectral Acceleration

References

$\mathrm{S}_{\mathrm{s}}=$

1.5

ASCE 7-05 Chapter 22

$\mathrm{S}_{1}=$

0.6

ASCE 7-05 Chapter 22

Site Coefficient

$F_{\mathrm{a}}=1$

ASCE 7-05 Table 11.4-1

$F_{v}=1$

ASCE 7-05 Table 11.4-2

Importance Factor

1

1

Table 4.1.1(a)

Type of Structure

$R_{i}=$ 2 Table 4.1.1(b) 
$R_{c}=$

1

Table 4.1.1(b)

A-Dynamic Model

1- Calculation of freeboard

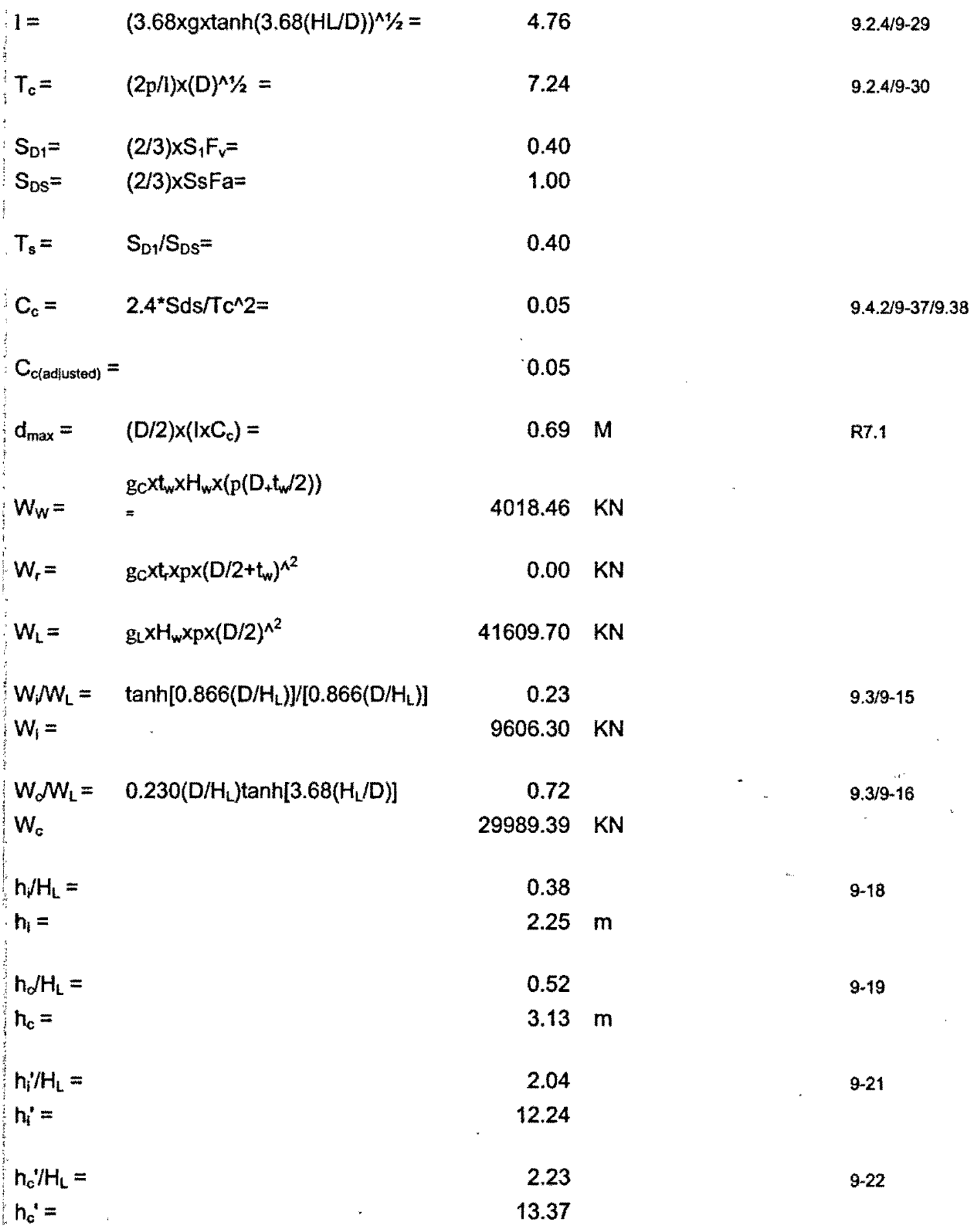




\begin{tabular}{|c|c|c|c|c|}
\hline $\mathrm{C}_{w}=$ & & 0.130 & & Fig. 9.10 \\
\hline$C_{1}=$ & $\operatorname{Cwx}\left(\mathrm{tw} /(10 \times R)^{\wedge 1 / 2}=\right.$ & 0.183 & & $9.3 .4 / 9-24$ \\
\hline$\omega_{i}=$ & $\left.\left(C_{1} / H_{L}\right) \times\left(1000 \times E_{c x} g / Y_{c}\right)^{\wedge 1 / 2}\right)=$ & 98.639 & & \\
\hline$T_{1}=$ & $2 \mathrm{p} / \omega_{1}=$ & 0.06 & $\mathbf{s}$ & $9.3 .4 / 9-25$ \\
\hline$c_{i}=$ & $\mathrm{Sd} 1 / \mathrm{Ti}=$ & 1.00 & & $9.41 / 9-33$ \\
\hline$e=$ & {$\left[0.151 \times\left(\mathrm{D} / \mathrm{H}_{\mathrm{L}}\right)^{\wedge} 2-0.1908\left(\mathrm{D} / \mathrm{H}_{\mathrm{L}}\right)+\right.$} & & 0.44 & $9.6 .2 / 9-45$ \\
\hline
\end{tabular}

\section{B- Earthquake Design Loads}

1- Dynamic lateral forces

$\begin{array}{lrrr}P_{W}= & I C_{i} \times W_{w} / R_{i}= & 893.1 \mathrm{KN} & 4.1 / 4-1 \\ P_{r}= & I C_{i} \times W r / R_{i}= & 0.0 \mathrm{KN} & 4.1 / 4-2 \\ P_{i}= & I C_{i} \times W / R_{i}= & 4803.1 \mathrm{KN} & 4.1 / 4-3 \\ P_{c}= & I C c x W c / R_{c}= & 1373.9 \mathrm{KN} & 4.1 / 4-4\end{array}$

2- Total base

shear

$V=\quad\left(\left(P_{i}+P_{w}+P_{r}\right)^{\wedge 2}+P_{c}^{\wedge}\right)^{\wedge 1 / 2}=\quad 5859.6 \mathrm{KN} \quad 4.1 / 4-5$

3- Bending moment on the entire tank cross section (EBP)

$M_{w}=\quad P_{w} \times h_{w}=2679.3 \mathrm{KM} . \mathrm{m} \quad 4.1 / 4-6$

$\begin{array}{lll}M_{\mathrm{r}}= & \mathrm{P}_{\mathrm{r}} \times \mathrm{h}_{\mathrm{r}}= & 0.0 \mathrm{KM} \cdot \mathrm{m}\end{array}$

$M_{1}=\quad P_{i} \times h_{1}=\quad 10807.1 \quad K M . m \quad 4.1 / 4-8$

$M_{c}=\quad P_{c} \times h_{c}=\quad 4298.1 \quad \mathrm{KM} . \mathrm{m} \quad 4.1 / 4-9$

$M_{b}=\quad\left(\left(M_{i}+M_{w}+M_{f}\right)^{\wedge 2}+M_{c}{ }^{\wedge}\right)^{\wedge 1 / 2}=\quad 14154.7 \quad K M . m \quad 4.1 / 4-10$

4- Overturning moment at the base of the tank (IBP)

$M_{i}^{\prime}=\quad P_{i} \times h_{i}^{\prime}=\quad 58812.2 \quad K M \cdot m \quad 4.1 / 4-11$

$M_{c}^{\prime}=\quad P_{c} h_{c}^{\prime}=\quad 18362.8, \quad K M . m$ 
The table below compares the results for this particular example. It can be seen that for this scenario, the impulsive pressure in the new provision is higher than the old. On the other hand, the convective pressure computed using $\mathrm{ACl} 350.3-06$ is lower than the previous provision. It cannot be concluded that the new provision would provide a more or less conservative estimation for the dynamic lateral pressures because there are many variations involved. It can be concluded that the new model (ACI 350.3-06) is more accurate as it computes the seismic response based on the exact given spectral accelerations, and it also requires a higher level of detail involving in the computation.

\begin{tabular}{|c|c|c|}
\hline Pressure & ACl350.3-01 & ACl350.3-06 \\
\hline$P_{W}$ & 714.5 & 893.1 \\
\hline$P_{i}$ & 3842.5 & 4803.1 \\
\hline$P_{C}$ & 1648.6 & 1373.9 \\
\hline
\end{tabular}

Table 3-2 Results - Comparison of ACI350.3-01 to ACI350.3-06 


\subsection{COMPARISON OF ACI 350.3-06 TO NZS 3106}

The impulsive and convective pressure is determined in the New Zealand standard by

$V_{H i}=C_{d}\left(T_{i}\right) W_{i} ;$ where the horizontal design action coefficient for mode $\mathrm{i}$.

$\mathrm{C}_{\mathrm{d}}\left(\mathrm{T}_{\mathrm{i}}\right)=\mathrm{C}\left(\mathrm{T}_{\mathrm{i}}\right) \mathrm{k}_{\mathrm{f}}\left(\mu, \xi_{\mathrm{i}}\right) \mathrm{S}_{\mathrm{p}}$; where the elastic site hazard spectrum for horizontal loading for the site subsoil type, and the relevant mode

$\mathrm{C}\left(\mathrm{T}_{\mathrm{i}}\right)=\mathrm{C}_{\mathrm{b}}\left(\mathrm{T}_{\mathrm{i}}\right) \mathrm{ZRN}\left(\mathrm{T}_{\mathrm{i}}, \mathrm{D}\right)$; where

$\mathrm{W}_{\mathrm{i}}=$ equivalent weight of tank and contents responding in particular mode of vibration considered;

$\mathrm{k}_{\mathrm{f}}\left(\mu, \xi_{\mathrm{i}}\right)=$ correction factor for NZS 1170.5 elastic site hazard spectrum to account for ductility and level of damping;

$\mathrm{S}_{\mathrm{p}}=$ structural performance factor, to be taken as 1.0;

$\mathrm{C}_{\mathrm{h}}\left(\mathrm{T}_{\mathrm{i}}\right)=$ spectral shape factor for the site subsoil type and the relevant mode;

$\mathrm{Z}=$ seismic zone hazard factor;

By combining the equations, the impulsive and convective pressure is

$$
\mathrm{V}_{\mathrm{Hi}}=\mathrm{C}_{\mathrm{h}}\left(\mathrm{T}_{\mathrm{i}}\right) \mathrm{ZRN}\left(\mathrm{T}_{\mathrm{i}}, \mathrm{D}\right) \mathrm{k}_{\mathrm{f}}\left(\mu, \xi_{\mathrm{i}}\right) \mathrm{S}_{\mathrm{p}} \mathrm{W}_{\mathrm{i}}
$$

In determining various parameters for the NZS standard, the period of vibration, $T$, must first be determined. The following impulsive modes are used unless a more detailed analysis is performed (DZ3106):

(a) Ground supported circular or rectangular tanks horizontal mode, assume $T_{I}=0.1 \mathrm{sec}$.

(b) Ground supported circular or rectangular tanks vertical mode, assume $T_{I}=0.1 \mathrm{sec}$.

(c) Fully ground-embedded circular or rectangular tank: $T_{I}=0$ sec, use $C_{h}\left(T_{1}\right)=C_{h}(0)$ (i.e. peak ground acceleration).

(d) Elevated tanks: The natural period of the tank and supporting structure shall be calculated in accordance with NZS 1170.5 . The flexibility of the tank walls may be neglected.

Clearly, the mode of vibration is either at 0 , or $0.1 \mathrm{sec}$, except for elevated tanks; whereas, in cases of ACI350.3-06, the mapped spectral accelerations are at short periods or $1.0 \mathrm{sec}$. These 
variations would therefore affect other parameters such as the spectral shape factor of the New Zealand standard.

For the convective component, the period of vibration $T_{\mathfrak{c}}$, would be determined graphically from Figure 4.1 below, where " $a$ " denotes the radius of the tank, and $l$ is the length of the side of the rectangular tank being considered.

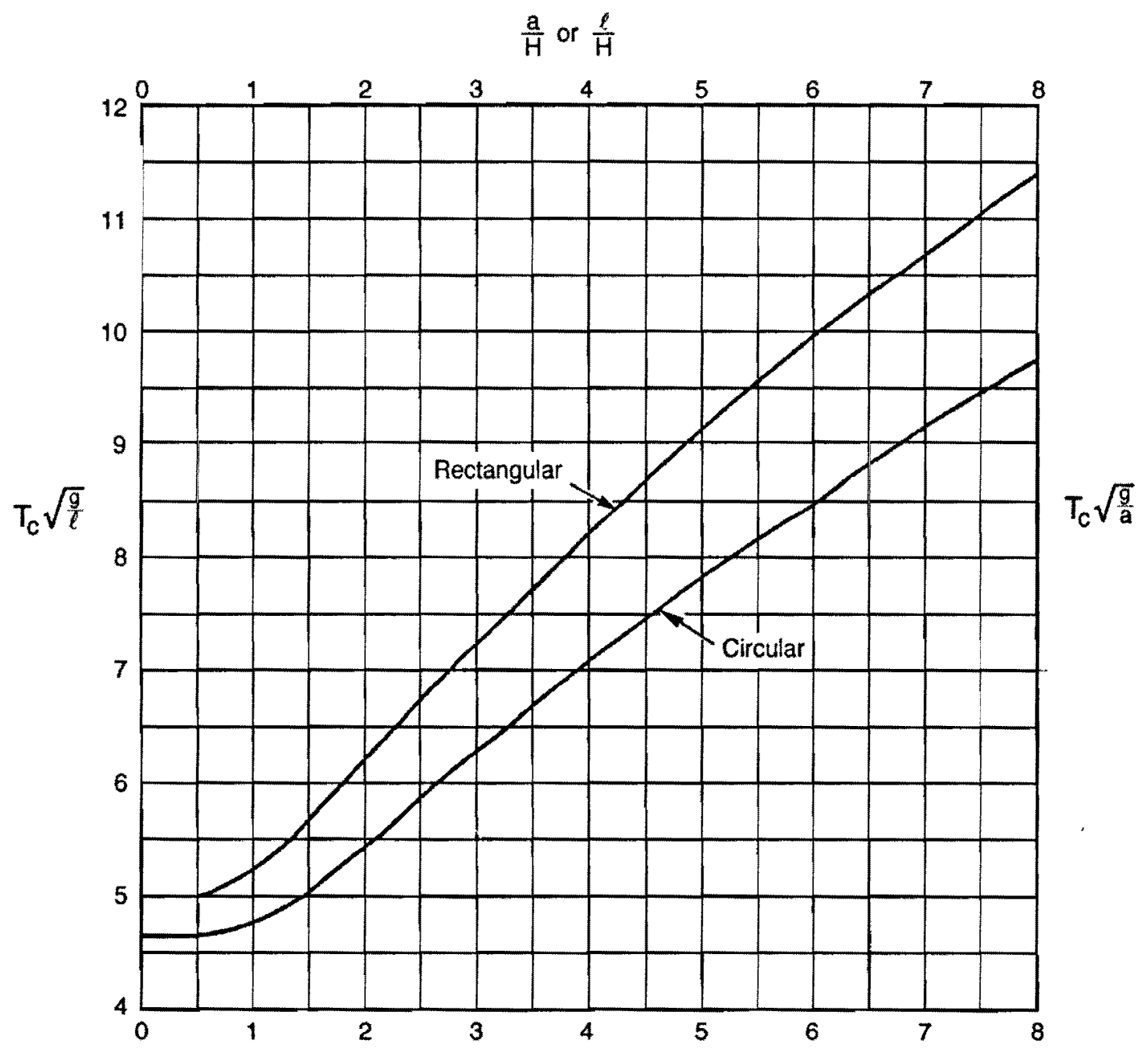

Fig. 4-1 Period $\left(\mathrm{T}_{c}\right)$ for fundamental sloshing model $(D Z 3106,2008)$

The spectral shape factor is a "smooth approximations to the shapes of the estimated hazard spectra for the various site classes" (NZS1170.5, 2004). New Zealand has selected a single spectral shape for all their rock sites for simplicity, and most of the data that was used to model the spectra were from Class B rock sites (NZS 1170.5, 2004). The classification of the sites are 
similar to that of ASCE7-05, with Class A as the strongest rock sites to peat and clays Class F; however NZS concludes at Class E, where the soil type is very soft soil, and it must have a depth of $10 \mathrm{~m}$ or more of materials with the shear-wave velocities lower than $150 \mathrm{~m} / \mathrm{s}$. Therefore, Class $F$ is not classified in the New Zealand Standard.

The spectra shape can be determined by various methods: modal response spectrum (MRS), numerical integration time history (NITH), and the equivalent static method.

\begin{tabular}{|c|c|c|c|c|c|c|}
\hline \multicolumn{7}{|c|}{ SPECTRAL SHAPE FACTOR $\left(\mathrm{C}_{h}\left(\mathrm{~T}_{\mathrm{i}}\right)\right)$} \\
\hline & $\mathrm{T}=0$ & $0<\mathrm{T} \leq 0.1$ & $0.1<\mathrm{T}<0.3$ & $0.3 \leq \mathrm{T} \leq 1.5$ & $1.5<\mathrm{T} \leq 3$ & $3<\mathrm{T}$ \\
\hline Class A \& B & 1 & $1.0+1.35(\mathrm{~T} / 0.1)$ & 2.35 & $1.60(0.5 / \mathrm{T})^{0.75}$ & $1.05 / \mathrm{T}$ & $3.15 / \mathrm{T}^{2}$ \\
\hline Class C & 1.33 & $1.33+1.60(\mathrm{~T} / 0.1)$ & 2.93 & $2.0(0.5 / \mathrm{T})^{0.75}$ & $1.32 / \mathrm{T}$ & $3.96 / \mathrm{T}^{2}$ \\
\hline
\end{tabular}

Table 4-1(A) Spectral Shape Factor for Class A, B, C (NZS1170.5, 2004)

SPECTRAL SHAPE FACTOR $\left(\mathrm{C}_{\mathrm{h}}\left(\mathrm{T}_{\mathrm{i}}\right)\right)$

\begin{tabular}{|c|c|c|c|c|c|c|}
\hline & $\mathrm{T}=0$ & $0<\mathrm{T} \leq 0.1$ & $0.1<\mathrm{T}<0.56$ & $0.56 \leq \mathrm{T} \leq 1.5$ & $1.5<\mathrm{T} \leq 3$ & $3<\mathrm{T}$ \\
\hline Class D & 1 & $1.12+1.88(\mathrm{~T} / 0.1)$ & 3 & $2.4(0.75 / \mathrm{T})^{0.75}$ & $2.14 / \mathrm{T}$ & $6.42 / \mathrm{T}^{2}$ \\
\hline
\end{tabular}

Table 4-1(B) Spectral Shape Factor for Class D (NZS1170.5, 2004)

\begin{tabular}{|c|c|c|c|c|c|c|}
\hline \multicolumn{7}{|c|}{ SPECTRAL SHAPE FACTOR $\left(\mathrm{C}_{\mathrm{h}}\left(\mathrm{T}_{\mathrm{i}}\right)\right)$} \\
\hline & $\mathrm{T}=0$ & $0<\mathrm{T} \leq 0.1$ & $0.1<\mathrm{T}<1$ & $1 \leq \mathrm{T} \leq 1.5$ & $1.5<\mathrm{T} \leq 3$ & $3<\mathrm{T}$ \\
\hline Class E & 1.12 & $1.12+1.88(\mathrm{~T} / 0.1)$ & 3 & $3.0 / \mathrm{T}^{0.75}$ & $3.32 / \mathrm{T}$ & $9.96 / \mathrm{T}^{2}$ \\
\hline
\end{tabular}

Table 4-1(C) Spectral Shape Factor for Class E (NZS1170.5, 2004)

For equivalent static method, the spectral shape factors are:

For $0 \leq \mathrm{T}<0.4, \mathrm{C}_{\mathrm{h}}(\mathrm{T})=1.89$ Class $\mathrm{A} \& \mathrm{~B}$;

For $0 \leq \mathrm{T}<0.4, \mathrm{C}_{\mathrm{h}}(\mathrm{T})=2.36$ Class $\mathrm{C}$

For $0 \leq \mathrm{T}<0.56, \mathrm{C}_{\mathrm{h}}(\mathrm{T})=3.0$ Class $\mathrm{D}$

For $0 \leq \mathrm{T}<1, \mathrm{C}_{\mathrm{h}}(\mathrm{T})=3.0$ Class $\mathrm{E}$

The spectral shape factors are also shown graphically below. 


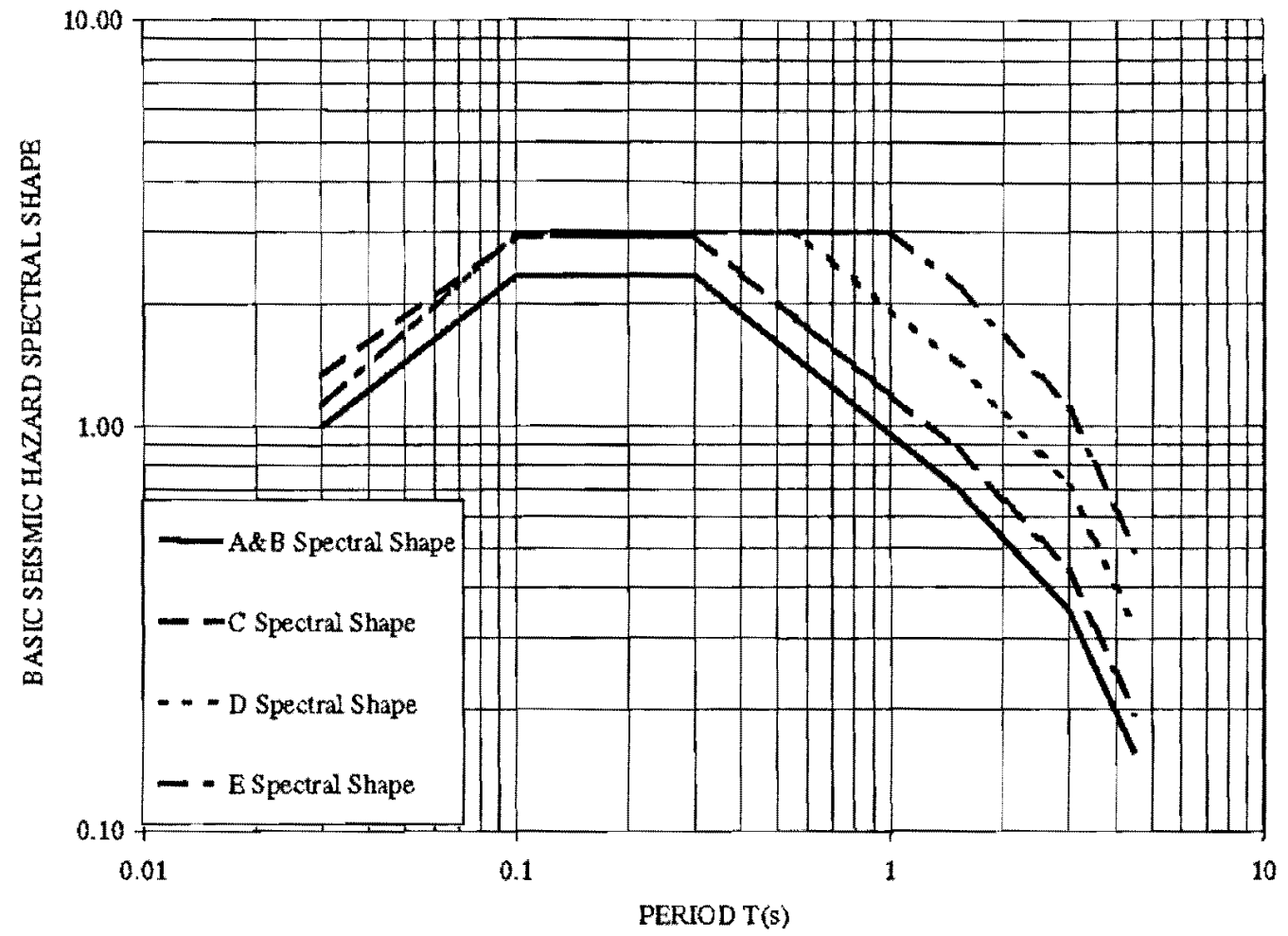

FIG.4-2(A) $C_{h}(T)$ for the Modal Response Spectrum (MRS) and Numerical Integration Time History Methods (NITH) (NZS1170.5,2004) 


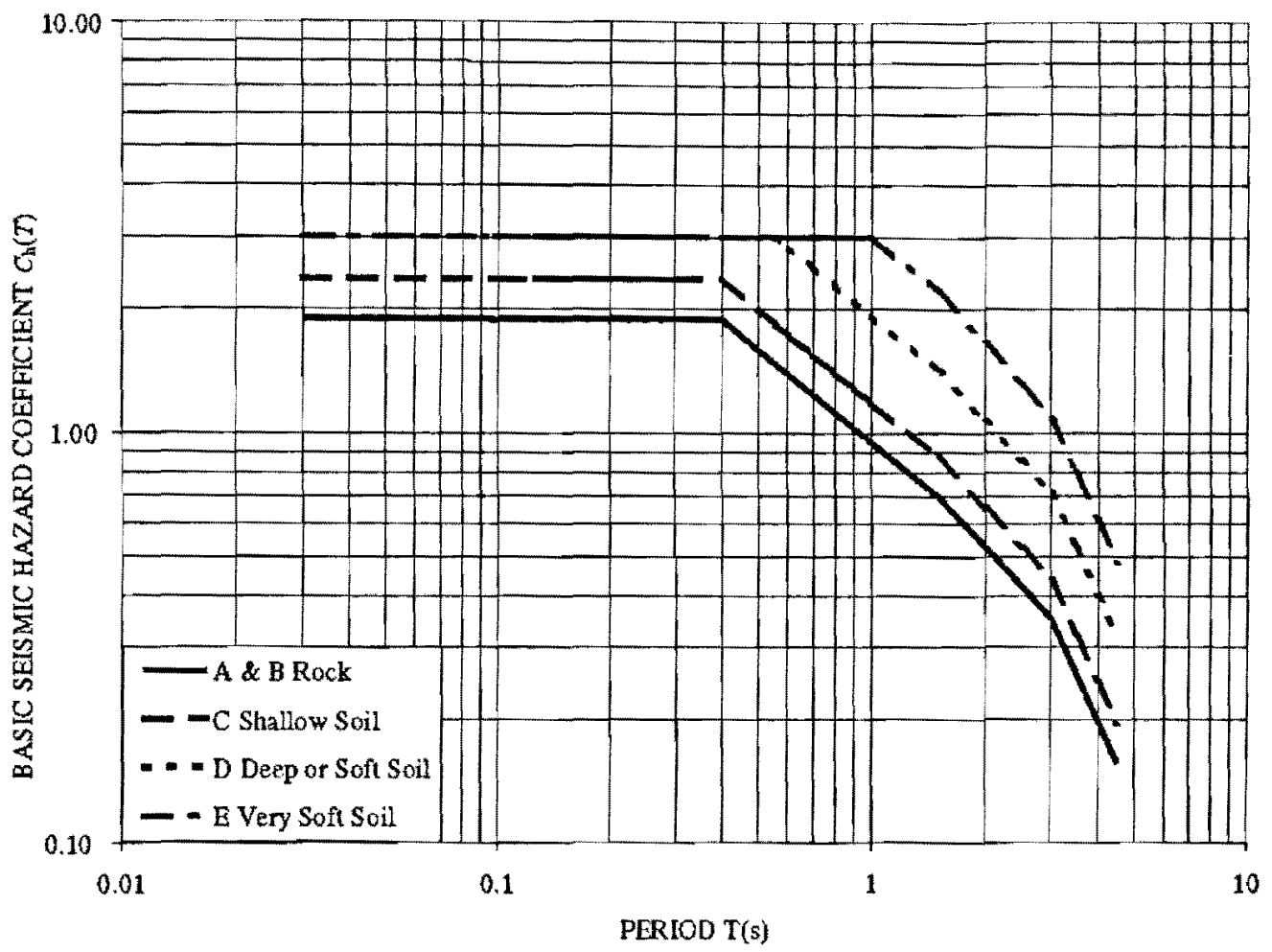

FIG.4-2(B) $C_{h}(T)$ for the Equivalent Static Method (NZS1170.5, 2004)

The computations of the loads of NZS 3106 are similar to those of ACI350.3-01, and therefore are very different from $\mathrm{ACl} 350.3-06$. The minimum $\mathrm{Z}$ value outlined in the NZS standard is 0.13 to ensure a margin against collapse in earthquakes that may occur in low seismic areas without identification of pre-existing surface faults; whereas the minimum $\mathrm{Z}$ value of $\mathrm{ACI} 350.3$ 01 is 0.075 for seismic zone 1 , which is the lowest seismic zone. For ACl350.3-06, there is no seismic zone factor $\mathrm{Z}$ as mentioned in Section 3.

Another difference between ACI350.3-06 and the NZS is the response modification factor, which ACI350.3-06 accounts for the type of tanks (for example fixed, hinged, or anchored). NZS does not account for the various types of structures, which could significantly overestimate the impulsive pressures by up to a factor of 3.25 .

NZS has a return period factor, denoted by $R$, used to scale any return periods other than 500 years. The values for the return period factor have been obtained by creating a representation line through various hazard curves for different locations as shown below. The return factor is similar to the importance factor of the ACI350.3-06. Where the design has a high importance 
level, a higher return period would be designed for, and that would be factored by the return period factor $R$ in the NZS 3106.

\section{$S A(0.5$ s) VARLATION WITH RETURN PERIOD}

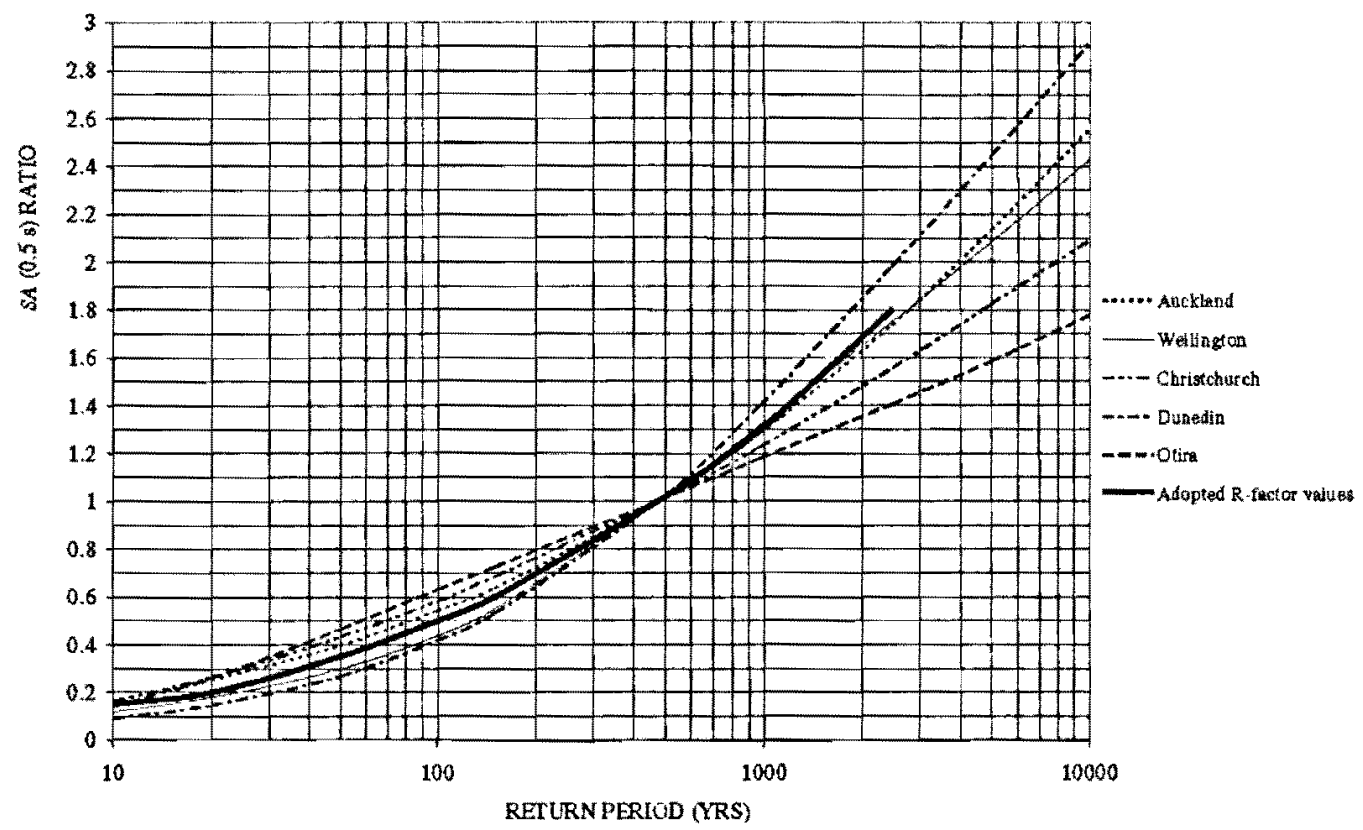

FIG.4-3 Comparison of Proposed R-Factors for New Zealand with Hazard Curves for 0.5s Spectral Accelerations (NZS1170.5, 2004)

Another factor that NZS has in their standard is the near-fault factor, $N\left(T_{i}, D\right)$. This factor is the result of the near-fault effects which is defined by a $20-\mathrm{km}$ radius within a major fault. Such effects are not accounted for in models used to estimate the seismic hazards, and it could significantly underestimate the problem if not considered (NZS1170.5, 2004).

Some of the near-fault effects are directivity and polarization. Earthquake directivity is the focusing of wave energy along the fault in the direction of rupture, and polarization is where the orientation of oscillations is in the plane perpendicular to a transversal wave's direction of travel. Other effects are fault-fling and hanging wall effects. The factor for near-fault effects can be determined as follows:

$N\left(T_{i}, D\right)=N_{\max }(T)$ for $D<2-k m$;

$\mathrm{N}\left(\mathrm{T}_{\mathrm{i}}, \mathrm{D}\right)=1+\left[\mathrm{N}_{\max }(\mathrm{T})-1\right][20-\mathrm{D}] / 18$ for $2-\mathrm{km}<\mathrm{D}<20-\mathrm{km}$ 
$N\left(T_{i}, D\right)=1$ for $20-k m<D$; where

$\mathrm{D}$ is the distance between the fault to the area under analysis;

$\mathrm{N}_{\max }=1$ for $1.5 \leq \mathrm{T}<2$;

$\mathrm{N}_{\max }=1.12$ for $2 \leq \mathrm{T}<3$;

$\mathrm{N}_{\max }=1.36$ for $3 \leq \mathrm{T}<4$

$\mathrm{N}_{\max }=1.60$ for $4 \leq \mathrm{T}<5$;

$\mathrm{N}_{\max }=1.72$ for $5 \leq \mathrm{T}$

The New Zealand standard has a correction, $\mathrm{k}_{\mathrm{f}}$, and this factor is to account for the ductility, $\mu$, and the damping level, $\xi$. The displacement ductility factor is dependent on the design limit state, whether ultimate or serviceability. NZS 3106 only allows serviceability loads, and they govern the design of many components of liquid-containing structures, but the standard requires the design for ultimate limit state as well to maintain the consistency with the design procedures used for other structures. As mentioned earlier, the correction factor is affected by ductility; therefore, higher ductility implies a low correction factor which results in a low impulsive. pressure. The ductility factors are shown below in Table 4-2.

\begin{tabular}{|l|c|}
\hline \multicolumn{1}{|c|}{ Response } & Mode Ductility Factor \\
\hline Reinforced or Prestressed Concrete Tanks on Grade or Embedded & 1.25 \\
\hline Horizontal impulsive modes, ULS loads & 1 \\
\hline Horizontal impulsive modes, SLS loads & 1.25 \\
\hline Vertical impulsive mode, ULS loads & 1 \\
\hline Vertical impulsive mode, SLS loads & 1 \\
\hline Convective mode, all & As appropriate for support structure \\
\hline Elevated Tanks & \\
\hline
\end{tabular}

Table 4-2 Displacement Ductility Factor (DZ 3106, 2008)

Another factor which affects the correction factor is the damping level, $\xi$. The damping levels are typically taken as $5 \%$ for impulsive and $0.5 \%$ for the estimation of the convective pressure, which are similar to ACl350.3-06. In both codes, where the damping levels are other than the latter, a correction factor is applied, which are $\mathrm{k}_{f}$ for NZS 3601 and $\eta$ for ACl350.3-06, although 
$\mathrm{k}_{\mathrm{f}}$ corrects for both ductility and damping levels simultaneously. The correction factor is determined in accordance with Table 4-3.

\begin{tabular}{|c|c|c|c|c|c|c|c|c|}
\hline \multirow{2}{*}{ Ductility } & \multicolumn{10}{|c|}{$\mathrm{k}_{\mathrm{f}}$} \\
\cline { 2 - 9 } & $\xi=0.5 \%$ & $\xi=1 \%$ & $\xi=2 \%$ & $\xi=5 \%$ & $\xi=10 \%$ & $\xi=15 \%$ & $\xi=20 \%$ & $\xi=30 \%$ \\
\hline 1 & 1.67 & 1.53 & 1.32 & 1 & 0.76 & 0.64 & 0.56 & 0.47 \\
\hline 1.25 & 1.08 & 1.04 & 0.96 & 0.82 & 0.67 & 0.58 & 0.52 & 0.44 \\
\hline 2 & 0.91 & 0.89 & 0.84 & 0.75 & 0.63 & 0.55 & 0.5 & 0.43 \\
\hline
\end{tabular}

Table 4-3 Correction Factor for Displacement Ductility and Damping Levels (DZ 3106, 2008)

Finally, the last component is the equivalent weight for the impulsive and convective components. The graphs of the equivalent weights are very similar between ACI-350.3-06 and NZS 3106. It cannot be determined whether the two standards are identical because there are no equations provided in the standards. It can be seen below that the functions are almost identical, if they are not identical.

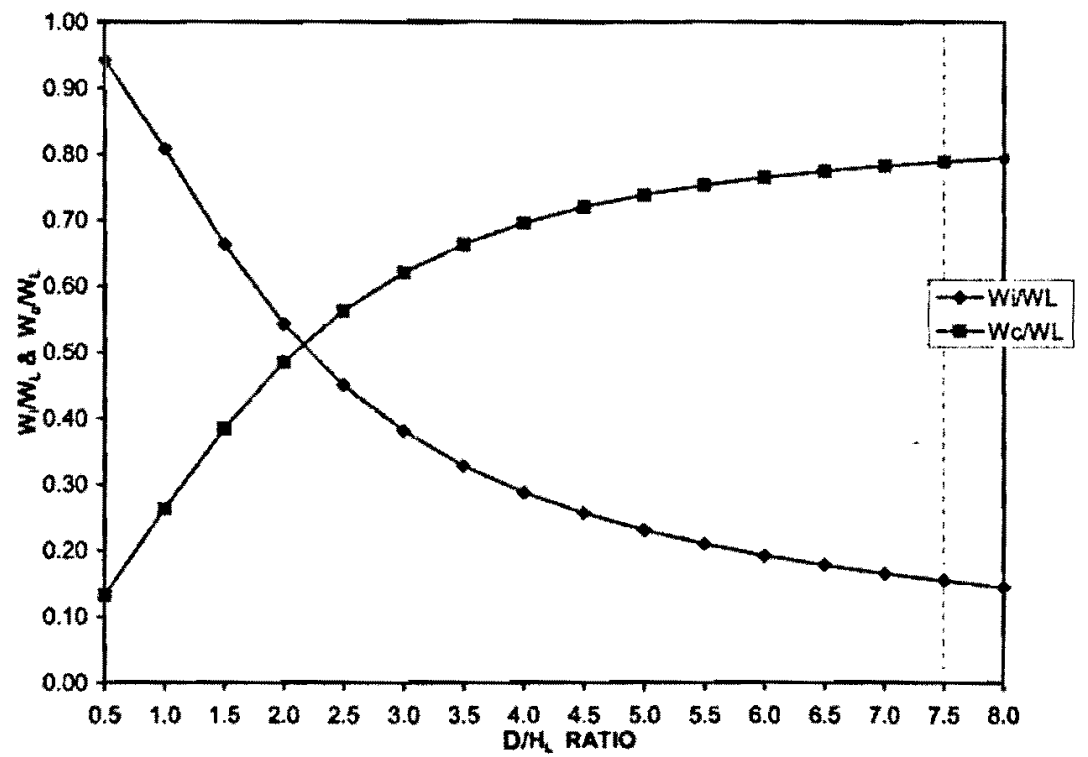

Fig.4-4 ACI350.3-06 Equivalent Weights for Impulsive and Convective (ACI350.3-06, 2006) 


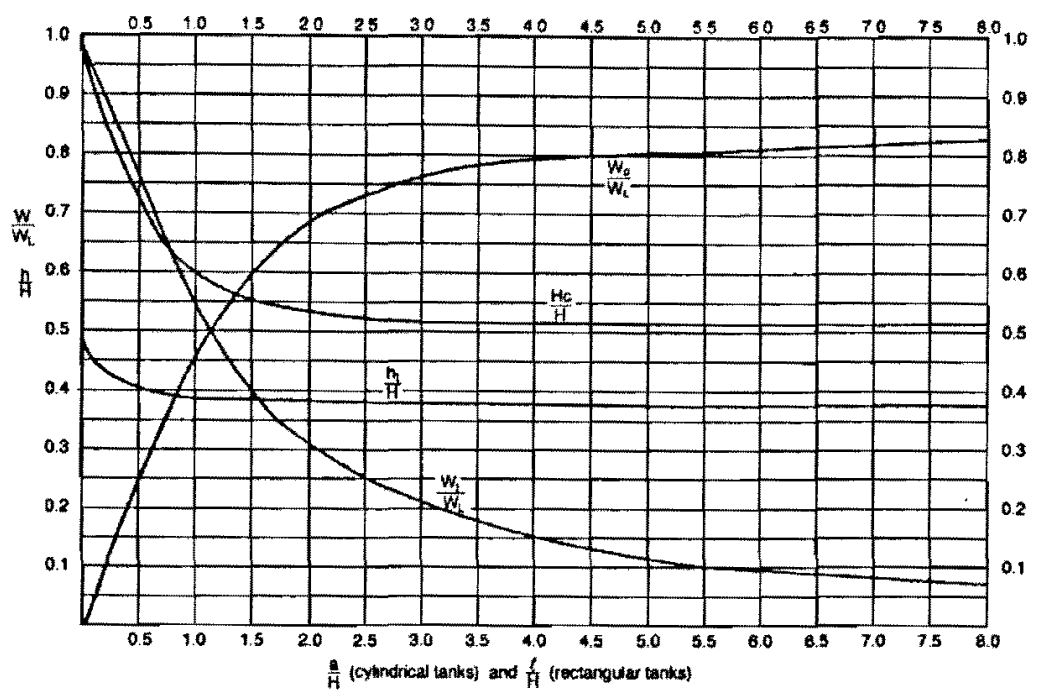

Fig.4-5 NZS 3106 Equivalent Weights of Impulsive and Convective $(D Z 3106,2008)$

Example 3.1 was re-computed based on the New Zealand standard to compare the similarities and differences amongst the two standards and the results are shown in Table 4-4.

\begin{tabular}{|c|c|c|}
\hline & NZS 3106 & $A C 1350.3-06$ \\
\hline$P_{W}$ & $1679 \mathrm{kN}$ & $893.1 \mathrm{kN}$ \\
\hline$P_{i}$ & $9030 \mathrm{kN}$ & $4803.1 \mathrm{kN}$ \\
\hline$P_{C}$ & $1186 \mathrm{kN}$ & $1373.9 \mathrm{kN}$ \\
\hline
\end{tabular}

Table 4-4 Results - Comparison of NZS3106 to ACI350.3-06

NZS 3106 is very similar to $\mathrm{ACI} 350.3-01$, and therefore, the differences are also the same as discussed in Section 3. A single value the response coefficient, C, of $\mathrm{ACl}$ 350.3-06 is equivalent to the product of $Z C_{h} k_{f} N$ of NZS 3106 . The site hazard coefficient $Z$ has already been discussed in Section 3, but the most significant factor which affects the results for the impulsive pressure is the response modification factor which exists in the ACI code but is not defined in the New Zealand. As previously discussed, the impulsive pressure could be overestimated up to 3.25 times. For this example, the response modification factor is 2 for the impulsive pressure, so the result from NZS is already overestimated by a factor of 2 , which has not included the seismic response variations. The result for the impulsive pressure is therefore significantly higher when applying the NZS3106. The convective pressure of the New Zealand standard is slightly lower than $\mathrm{ACI} 350.3-06$, and it is due to the variations in the seismic response and its ductility factor; 
however, the difference is minimal for the convective pressure as opposed to the impulsive pressure. Although $\mathrm{ACI}$ does not have a near fault factor, it might not require it since the seismic response is computed based on the exact spectral accelerations. 


\subsection{CONCLUSION}

Earthquake motion produces spectral accelerations that can cause failure to any type of structures including tanks, and therefore, the spectral acceleration is extremely important in estimating the pressure exerted onto the walls of the tank. The pressures exerted on walls are impulsive and convective, which can stress the tank wall and uplift it. The seismic response is influenced by many factors which include spectral accelerations, soil classifications and the period of vibration. Another factor which affects the estimation of the seismic loads is the type of support, whether the structure is anchored/unanchored, flexible, or rigid; moreover, unanchored flexible buried tanks yield the least loading for all types of tanks.

The latter various types of structure are not accounted for in the New Zealand Standard NZS 3106, and therefore the standard may have overestimated the loading due to seismic. NZS 3106 and $\mathrm{ACI}$ 350.3-01 share their similarities, so they also share their differences with $\mathrm{ACI}$ 350.3-06. One of the same differences is the zone hazard factor, $Z$, which does not exist in the ACI 350.306, and that major factor has made the new ACI 350.3-06 more dominating than the previous standards. That revision has allowed a more precise estimation as it utilizes the specific spectral accelerations for the site; whereas, the $Z$ value, in the ACI 350.3-01 and the NZS 3106, is used to represent a whole range of spectral accelerations.

Not only does NZS 3106 have differences with ACI 350.3-06, it has a major difference with both ACI 350.3-01 and ACI 350.3-06. In fact, the difference is so significant such that the impulsive, roof, and wall pressures due to seismic can be estimated up to triple the loading estimated by the ACI. The example in the previous section has shown that estimations from NZS 3106 have approximately doubled the estimation from both $\mathrm{ACI}$ codes because of the type of structure that affect the response, and the response modification factor accounts for such behaviour.

Although the selected codes vary by jurisdiction, they mainly adopted the models and theories that were developed decades ago. With some modifications, the standards are now readily available for professional engineers to utilize and base their designs upon. 


\section{References:}

ACI 350.3-06, 2006. Seismic design of liquid-containing concrete structures (ACI 350.3-06) and commentary (350.3R-06). American Concrete Institute (ACI) Committee 350. Environmental Engineering Concrete Structures, Farmington Hills, Mich.

ACI 350.3-01, 2006. Seismic design of liquid-containing concrete structures (ACI 350.3-01) and commentary (350.3R-01). American Concrete Institute (ACI) Committee 350. Environmental Engineering Concrete Structures, Farmington Hills, Mich.

American Society of Civil Engineers (ASCE). 1984. Fluid/Structure Interaction During Seismic Excitation. Committee on Seismic Analysis.

American Society of Civil Engineers (ASCE), 2005. Minimum Design Loads for Buildings and Other Structures. ASCE 7-05. Reston, Va.

Haroun, M.A. 1984. Stress Analysis of Rectangular Walls Under Seismically Induced Hydrodynamic Loads. Bulletin of the Seismological Society of America, V. 74, No.3.

Housner, G.W. 1963. The dynamic behaviour of water tanks. Bulletin of the Seismological Society of America.

New Zealand Standard. 2008. Code of practice for concrete structures for the storage of liquid DZ 3106. Committee P 3106, Standards New Zealand, Wellington.

New Zealand Standard. 2004. Structural Design Actions NZS 1170.5 Supplement 1:2004. Technical Committee BD-006-04-11, Standards New Zealand, Wellington.

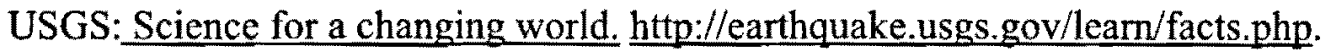

Veletsos, A.S. and Shivakumar, P. 1996. Dynamic response of tanks containing liquids or solids. Rice University. Computations Mechanics Publications, Houston. 